\title{
Espiritualidade e Medicina: Interfaces e Diálogos
}

\author{
Fonseca, Maria Silian Mandu da; Bueno, Maria Eduarda; Schliemann, Ana Laura \\ Faculdade de Ciências Médicas da Saúde - PUC SP — silian.ma@gmail.com
}

Introdução: diante da busca de humanizar os cuidados na saúde e sabendo da importância da espiritualidade; que é a melhoria dos pensamentos, palavras e ações; buscou-se o entendimento da mesma diante do processo de adoecimento e cura de um paciente e sua família. Objetivos: identificar a produção cientifica sobre a "Relação entre Formação na Graduação em Medicina e a Espiritualidade" e as "Escalas em Saúde que avaliam a Espiritualidade em Pacientes com Doenças Graves e ou Potencialmente Fatais", existentes em períodos indexados nos banco de dados da LILACS e MEDLINE no período de 2006 a 2012. Metodologia: esse trabalho observou o método proposto por Silviera e Zago (2006) em sua revisão bibliográfica sobre Enfermagem e Câncer. o método propõe um primeiro acesso aos resumos no site da BVS na base de dados Medline e Lilacs a fim de identificar os artigos relacionados com o objetivo proposto, os parcialmente relacionados e os não relacionados. Posteriormente, com os artigos relacionados fez-se um resumo de cada um deles com as seguintes características: tema central, método utilizado, principais resultados. Resultados: no total foram analisados 23 resumos de artigos sobre o tema "Relação entre a Formação na Graduação em Medicina e a Espiritualidade", sendo 23 da base Medline e 0 da base Lilacs. do total, 7 artigos estavam relacionados aos objetivos do trabalho, 2 estavam parcialmente relacionados e 14 não estavam relacionados. dos artigos relacionados 1 avaliou a crença dos estudantes sobre a relação saúde e espiritualidade, 1 era uma carta citando criticas a um trabalho publicado falando sobre a influencias sofridas no resultado final, 5 mostraram formas de trabalhar esse assuntos com os estudantes e a sua importância. em relação ao tema "Escalas em Saúde que avaliam a Espiritualidade em Pacientes com Doenças Graves e ou Potencialmente Fatais", analisaram-se 45 resumos de artigos, sendo 42 da base Medline e 3 da base Lilacs. do total, 10 artigos estavam relacionados aos objetivos do trabalho, 17 parcialmente relacionados e 18 não relacionados. Frente aos dez resumos, apenas cinco avaliaram a opinião dos pacientes quanto ao inquérito sobre a espiritualidade durante a entrevista médica, a importância desta em sua vida, suas necessidades espirituais e religiosas relacionadas à saúde. e seis dos dez, buscaram o desenvolvimento e validação das escalas espiritualista. Conclusões: o tema espiritualidade em saúde ainda é pouco discutido no Brasil e na América Latina. É necessário um maior conhecimento médico sobre a espiritualidade e como abordá-la com o paciente, e esse conhecimento deveria ser iniciado durante a graduação. Portanto, se estudado o lado espiritual dos pacientes haverá uma maior humanização do processo de cura e relação médico paciente, pois, o conhecimento da humanização aperfeiçoa o trabalho do médico, que passa a levar em conta todos os aspectos da saúde e doença, cuidando do paciente como um todo.

Palavras-chave: espiritualidade, saúde, graduação, humanização, escalas de espiritualidade, pacientes

Fonseca, Maria Silian Mandu da; Bueno, Maria Eduarda; Schliemann, Ana Laura. Espiritualidade e Medicina: Interfaces e Diálogos. In: Anais do Congresso Internacional de Humanidades \& Humanização em Saúde [= Blucher Medical Proceedings, num.2, vol.1]. São Paulo: Editora Blucher, 2014. ISSN 2357-7282

DOI 10.5151/medpro-cihhs-10223 